\title{
Unilateral Twin Ectopic Pregnancy (Diamniotic-Dichorionic): A Rare Case
}

\author{
${ }^{1}$ Sunita Ghike, ${ }^{2} \mathrm{~S}$ Somalwar, ${ }^{3}$ Kajal Mitra, ${ }^{4}$ Sayali Kulkarni, ${ }^{5}$ Mugdha Ladikar \\ ${ }^{6}$ Niraj Baisakhiya, ${ }^{6}$ Glossy Sabharwal \\ ${ }^{1}$ Professor, Department of Obstetrics and Gynecology, NKP Salve Institute of Medical Sciences, Nagpur, Maharashtra, India \\ ${ }^{2}$ Lecturer, Department of Obstetrics and Gynecology, NKP Salve Institute of Medical Sciences, Nagpur, Maharashtra, India \\ ${ }^{3}$ Professor and Head, Department of Radiodiagnosis and Imaging, NKP Salve Institute of Medical Sciences, Nagpur, Maharashtra, India \\ ${ }^{4}$ Junior Resident II, Department of Obstetrics and Gynecology, NKP Salve Institute of Medical Sciences, Nagpur, Maharashtra, India \\ ${ }^{5}$ Junior Resident I, Department of Obstetrics and Gynecology, NKP Salve Institute of Medical Sciences, Nagpur, Maharashtra, India \\ ${ }^{6} J u n i o r$ Resident II, Department of Radiodiagnosis and Imaging, NKP Salve Institute of Medical Sciences, Nagpur, Maharashtra, India
}

Correspondence: Sunita Ghike, Professor, Department of Obstetrics and Gynecology, NKP Salve Institute of Medical Sciences, 57, 4A, Madhuban Apartment, Khare Town, Dharampeth, Nagpur-440010, Maharashtra, India, Phone: 9763726957 e-mail: sunita_dr@yahoo.co.in

\section{ABSTRACT}

Unilateral twin ectopic is a rare condition. Only 100 cases reported till date in the literature. A 34-year-old woman having secondary infertility reported to emergency with amenorrhea of one and half months and pain in abdomen. Her urine pregnancy test was positive and ultrasonography showed multiple (twin) ectopic gestational sacs in left adenexa. Color Doppler showed ring of fire sign encircling both the gestational sacs suggestive of twin ectopic pregnancy (diamniotic-dichorionic) in left adenexa. Exploratory laparotomy confirmed the diagnosis.

Keywords: Twin, Ultrasonography, Ectopic pregnancy.

\section{INTRODUCTION}

Ectopic pregnancy is a major health risk for women of child bearing age and if not diagnosed and treated properly can lead to life-threatening complications. Many factors increase the risk of ectopic pregnancy, important being pelvic inflammatory disease, adhesions, ART, etc. Twin ectopic is a rare condition with only 100 diagnosed cases worldwide. ${ }^{1}$ Unilateral twin ectopic gestation is estimated to occur approximately one in 200 of all ectopic gestations. ${ }^{1}$

A 34-year-old woman, married since 15 years, gravid 3 para 2 with only one live issue, full-term normal delivery, female, 11 years, not using any contraceptive and not investigated for secondary infertility, reported on 17 August 2010 to our department as emergency patient with history of amenorrhea of one and half months, and pain in abdomen 6 to 7 hours prior to admission. There was no history of vaginal bleeding or fainting attack. Her last menstrual period was on 4 July 2010 and was overdue by 13 days. Her previous cycles were eumenorrheic. There was no history suggestive of any major medical or surgical illness in past including tuberculosis. Personal and family history were not contributory. Her general examination did not reveal any abnormality except she had pallor and tachycardia 110/minute regular with 110/70 mm Hg of blood pressure.

On per abdominal examination, there was no tenderness or palpable mass. Per speculum examination was normal. On per vaginal examination uterus was normal size, retroverted, right fornix clear, in left fornix there was fullness and mild tenderness but cervical movements were nontender. Her investigations were sent, urine pregnancy test was done which was seen positive. Her USG revealed normal size uterus with pseudo sac. Both ovaries were normal. There were well-defined two extrauterine gestational sacs in left adenexal region. On color Doppler, both gestational sacs showed ring of fire encircling the gestational sacs, thus confirming the diagnosis of multiple (twin) ectopic pregnancy on left side (Figs 4A and B). Fluid collection was noted in Pouch of Douglas. Her other investigations were within normal limit, so she was subjected for emergency exploratory laparotomy. Intraoperatively, there was moderate hemoperitoneum, uterus was bulky, and in left fallopian tube there were two sacs of size $4 \times 4 \mathrm{~cm}$ and $4 \times 3 \mathrm{~cm}$ (Fig. 1). Leftsided salpingectomy and bilateral round ligament plication were done. The patient did well postoperatively, and was discharged on 7th day. The histopathological examination also confirmed the diagnosis. Left fallopian tube- - two masses size $3.5 \times 1.5 \times$ $1 \mathrm{~cm}$ and $2.5 \times 2 \times 1 \mathrm{~cm}$ with HP report of tubal pregnancy (Fig. 2). Endometrium was showing secretory activity with focal Arias-Stella reaction and decidualization (Fig. 3).

\section{DISCUSSION}

Incidence of ectopic pregnancy is increasing since 1970 and more incidence is seen in developing countries (2-6\%). ${ }^{1}$ Several factors are thought to increase the risk of ectopic pregnancy, pelvic inflammatory disease with maximum risk and others being advanced maternal age, adhesions, operative trauma, in vitro fertilization. ${ }^{2,9}$ 


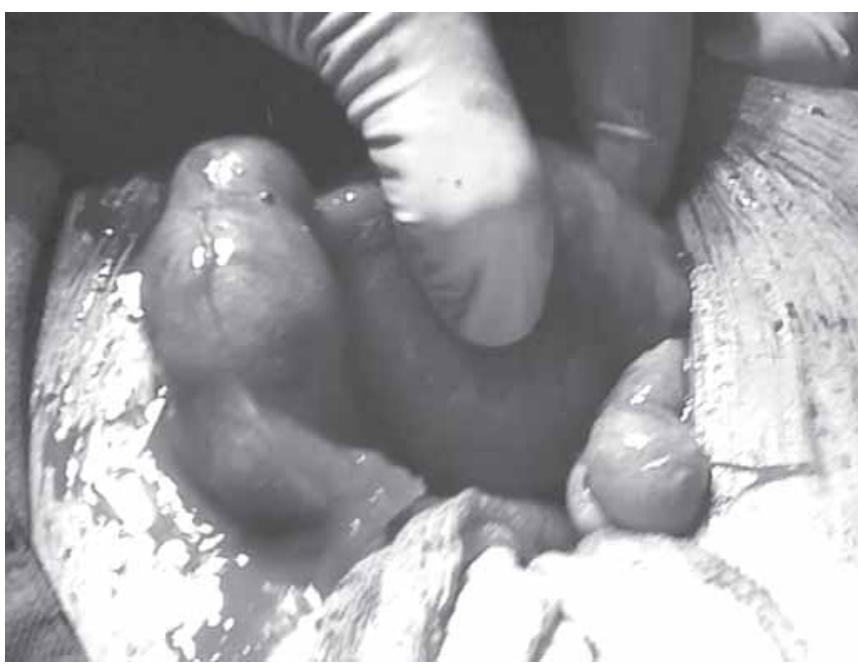

Fig. 1: Left fallopian tube showing two masses (swellings) of unilateral twin ectopic gestation

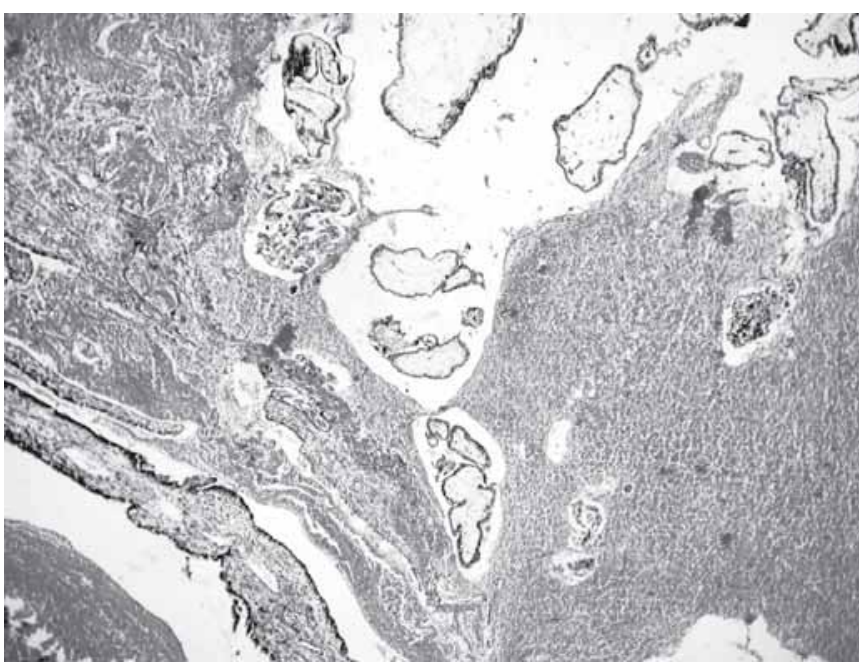

Fig. 2: Cut section of left fallopian tube showing partly flattened mucosa, mucosal folds with edematous changes, lumen containing chorionic villi, cysts and syncytiotrophoblast

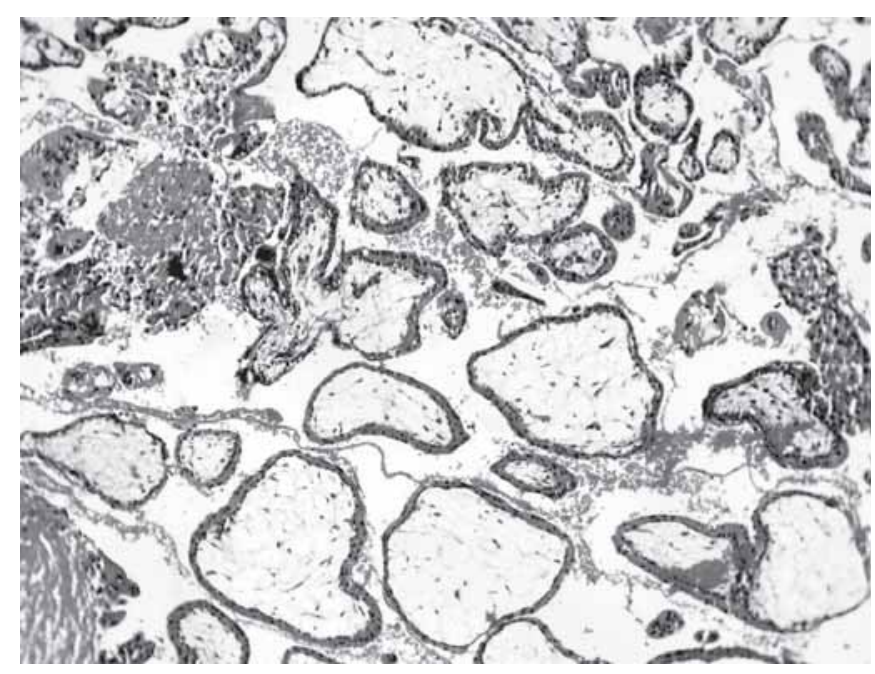

Fig. 3: Chorionic villi with secretary changes and focal Arias-Stella reaction and decidualization
Twin ectopic pregnancies are heterotopic, i.e. intrauterine and extrauterine pregnancy with estimated incidence of one in $7000 .^{3}$ Unilateral twin ectopic pregnancy is a rare condition, first described in 1891 by De Ott. ${ }^{4,11}$ Live twin ectopic pregnancies are rare with incidence of one in $1,25,000 .^{5}$ Approximately, only 100 twin ectopic pregnancies have been reported till date. There are less than 10 unilateral ectopic twin pregnancies reported with beating hearts in both embryos. In 1994, Gualandi et $\mathrm{al}^{6}$ reported the first case of unilateral tubal twin pregnancy with cardiac activity in both embryos by endovaginal USG. In 2001, Goker et al reported a case of unilateral twin ectopic pregnancy following an IVF cycle. ${ }^{7}$ In 2002, Hanchate et $\mathrm{al}^{8}$ reported a patient with a live twin ectopic pregnancy with no predisposing factors.

Transvaginal USG is recommended for detailed evaluation as resolution for uterine and adenexal structure is superior. The diagnostic markers are extrauterine gestational sacs, adenexal mass and ring of fire sign encircling the gestational sacs.

Treatment depends on the clinical presentation, size, complications, and include conservative, medical or surgical intervention.
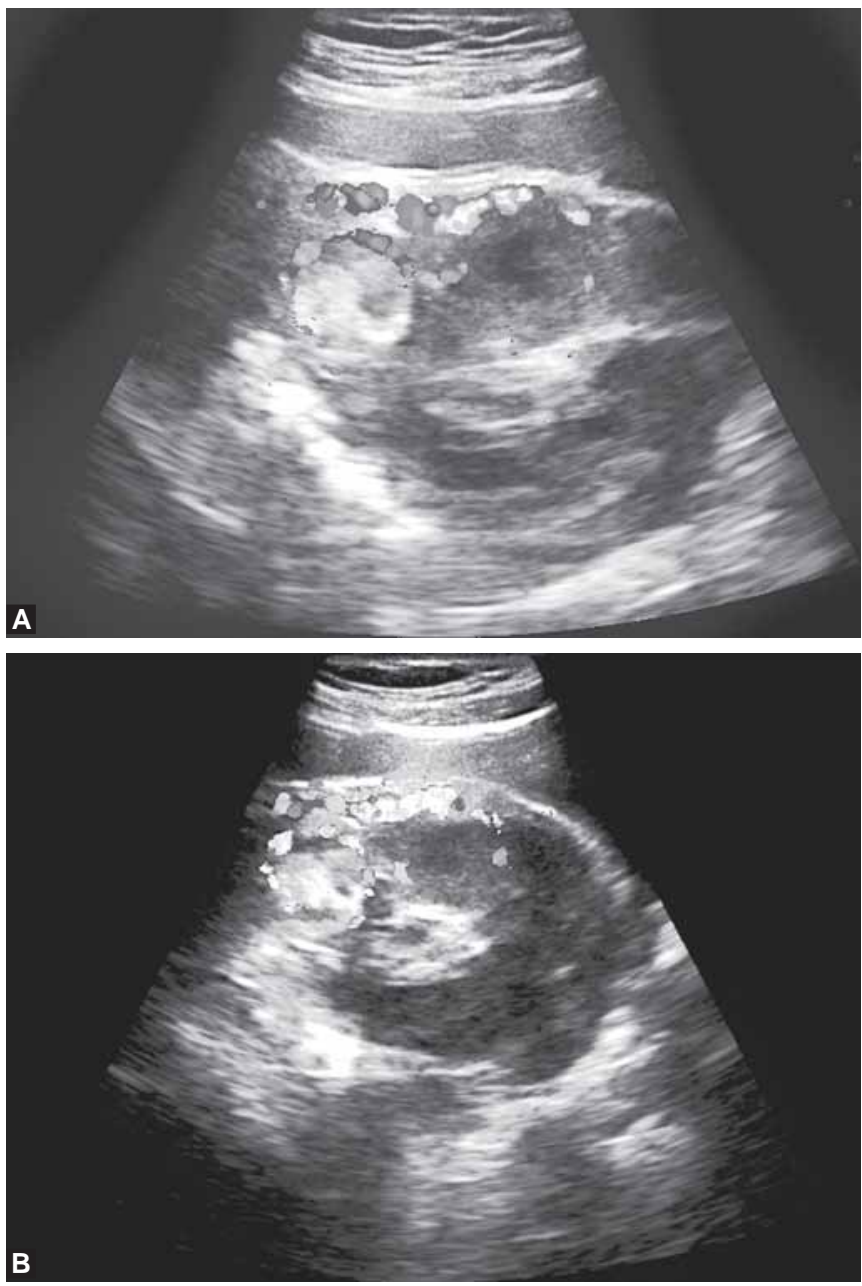

Fig. 4A and B: Sonography with color Doppler imaging two distinct heterogenous mass like lesions with peripheral intense vascularity resembling "Rings of fire" suggesting the diagnosis of unilateral twin ectopic pregnancy 
In our case the patient had pallor and tachycardia. On per vaginal examination, there was fullness in Pouch of Douglas and tenderness in fornices. Transvaginal USG was suggestive of uterus with pseudo sacs and gestational sacs identified in left adenexal region. Both sacs were in close proximity to each other, both showed ring of fire sign encircling gestational sacs on color Doppler, and fluid in POD confirming the diagnosis of twin ectopic pregnancy (see Figs 4A and B). As patient was not hemodynamically stable, she was taken for emergency laparotomy (see Fig. 1) and left-sided salpingectomy was done. Histopathological examination of uterine endometrium was suggestive of secretory endometrium with focal Arias-Stella reaction and decidualization (see Fig. 3). On left-sided fallopian tube with partly flattened mucosa, mucosal folds with edematous changes, lumen containing chorionic villi, cysts and syncytiotrophoblastic cells areas of hemorrhages (see Fig. 2).

Though rare, twin ectopic pregnancy must be looked for while doing USG scanning, especially in patients having IVF treatment and PID.

In our patient, the probable cause of ectopic pregnancy was undiagnosed pelvic inflammatory disease as she had long standing infertility of 11 years. ${ }^{10}$

\section{REFERENCES}

1. Shwayder JM, Mahoney V, Bersinger DE. Unilateral twin ectopic pregnancy managed by operative laparoscopy: A case report. J Reprod Med 1993;38:314-16.
2. Parker J, Hewson AD, Calder-Mason T, Lai J. Transvaginal ultrasound diagnosis or live twin tubal ectopic pregnancy. Australas Radiol 1999;43:95-97.

3. Lysons EA, Levi CS, Dashfsky SM. The first trimester ectopic pregnancy. Clinical importance. In: Runack CM, Wilson SR. Carbonueau JW (Eds). Diagnostic ultrasound (2nd ed). St Louis, MO:CV Mosby 1998:998.

4. De Ott D. A case of unilateral tubal twin gestation. Annales de gynaecologic obstetrique 1891;36:304.

5. Abrams RA, Kanter AE. Bilateral simultaneous extrauterine pregnancy. Am J obstet gynaecol 1948;56:1198-1200.

6. Gualandi M, Steemers N, de Keyser JL. First reported case of preoperative ultrasonic diagnosis and laparoscopic treatment of unilateral, twin tubal pregnancy. Rev Fr Gynecol Obstet 1994;89:134-36.

7. Göker EN, Tavmergen E, Ozçakir HT, Levi R, Adakan S. Unilateral ectopic twin pregnancy following an IVF cycle. J Obstet Gynaecol Res 2001;27:213-15.

8. Hanchate V, Garg A, Sheth R, Rao J, Jadhav PJ, Karayil D. Transvaginal sonographic diagnosis of live monochorionic twin ectopic pregnancy. J Clin Ultrasound 2002;30:52-56.

9. Charles J Rolle, Clifford Y Wai, Rojer Bawdon, Rigoberto Sanots-Ramos, Barbara Hoffman. Case report: Unilateral twin ectopic pregnancy in a patient with history of multiple sexually transmitted infections. Hindawi Publishing Corporation, Infectious Diseases in Obstetrics and Gynaecology, Volume 2006, Article ID 10306, pages 1-3. DOI. 10. 1155/DOG/2006/ 10306.

10. Akinbiyi AA, Schweitzer K. Spontaneous unilateral twin ectopic pregnancy with fetal heart beats in a patient with a single episode of Chlamydia trachomatis. J Gynecol Surg 2007;23:147-52.

11. George M, Nadarajah S, Ong CL. Case report: Unilateral twin ectopic pregnancy. JHK coll Radiol 2010;12:186-89. 